\title{
Demonstration of boron arsenide heterojunctions: A radiation hard wide band gap semiconductor device
}

\author{
Y. Gong, ${ }^{1, a)}$ M. Tapajna, ${ }^{1}$ S. Bakalova, ${ }^{1}$ Y. Zhang, ${ }^{2}$ J. H. Edgar, ${ }^{2}$ Y. Zhang, ${ }^{3}$ M. Dudley, ${ }^{3}$ \\ M. Hopkins, ${ }^{4}$ and M. Kuball ${ }^{1}$ \\ ${ }^{1}$ H.H. Wills Physics Laboratory, University of Bristol, Bristol BS8 1TL, United Kingdom \\ ${ }^{2}$ Department of Chemical Engineering, Kansas State University, Manhattan, Kansas 66506, USA \\ ${ }^{3}$ Department of Materials Science and Engineering, SUNY, Stony Brook, New York 11794, USA \\ ${ }^{4}$ Department of Electronic and Electrical Engineering, University of Bath, Bath BA2 7AY, United Kingdom
}

(Received 13 January 2010; accepted 12 May 2010; published online 4 June 2010)

\begin{abstract}
$\mathrm{B}_{12} \mathrm{As}_{2} / \mathrm{SiC} p n$ heterojunction diodes based on the radiation-hard $\mathrm{B}_{12} \mathrm{As}_{2}$ deposited on (0001) $n$-type $4 \mathrm{H}-\mathrm{SiC}$ via chemical vapor deposition were demonstrated. The diodes exhibit good rectifying behavior with an ideality factor of 1.8 and a leakage current as low as 9.4 $\times 10^{-6} \mathrm{~A} / \mathrm{cm}^{2}$. Capacitance-voltage measurements using a two-frequency technique showed a hole concentration of $\sim 1.8-2.0 \times 10^{17} \mathrm{~cm}^{-3}$ in $\mathrm{B}_{12} \mathrm{As}_{2}$ with a slight increase near the interface due to the presence of an interfacial layer to accommodate lattice mismatch. Band offsets between the $\mathrm{B}_{12} \mathrm{As}_{2}$ and $\mathrm{SiC}$ were estimated to be $\sim 1.06 \mathrm{eV}$ and $1.12 \mathrm{eV}$ for conduction band and valance band, respectively. (C) 2010 American Institute of Physics. [doi:10.1063/1.3443712]
\end{abstract}

Icosahedral boron arsenide $\left(\mathrm{B}_{12} \mathrm{As}_{2}\right)$ is a wide band gap boron-rich semiconductor $\left(E_{g} \approx 3.20 \mathrm{eV}\right.$ at room temperature ${ }^{1}$ ). Its structure is based on 12-boron-atom icosahedra residing at the lattice points of a rhombohedral unit cell, with an As-As chain lying along its [111] axis (the body diagonal) (Refs. 2 and 3) [Fig. 1(a)]. The boron atoms in the icosahedra are bonded by so-called three-centered bonds, i.e., a pair of electrons is shared among three boron atoms. As a consequence of this unique structure and bonding, $\mathrm{B}_{12} \mathrm{As}_{2}$ has extraordinary radiation tolerance via self-healing mechanisms. In addition, it has a high melting temperature, and excellent mechanical properties, making $\mathrm{B}_{12} \mathrm{As}_{2}$ highly attractive for applications under harsh conditions. Further details on the material properties of $\mathrm{B}_{12} \mathrm{As}_{2}$ can be found in Refs. $1-7$, and reference therein.

A key potential application of $\mathrm{B}_{12} \mathrm{As}_{2}$ is for compact solid-state thermal neutron detectors because ${ }^{10} \mathrm{~B}$ has one of the highest thermal neutron $(0.0259 \mathrm{eV})$ capture crosssections, $\sim 3840 \mathrm{~b}$ of all elements. ${ }^{8}$ When thermal neutrons are absorbed by ${ }^{10} \mathrm{~B}$, energetic ${ }^{7} \mathrm{Li}$ and ${ }^{4} \mathrm{He}$ ions form, predominantly via ${ }^{10} \mathrm{~B}+n \rightarrow{ }^{7} \mathrm{Li}(0.84 \mathrm{MeV})+{ }^{4} \mathrm{He}(1.47 \mathrm{MeV})$, and electron-hole pairs are created as the ${ }^{7} \mathrm{Li}$ or ${ }^{4} \mathrm{He}$ ions passing through the material. Compared with the present mature neutron detection technology employing gas-filled, proportional counters, or doped scintillating plastic fibers, solidstate neutron detectors would have reduced size and weight features that are beneficial for applications in portable devices or space. A further potential application is for betavoltaics, converting nuclear energy into electrical power, for small-scale long-lifetime batteries, e.g., remote sensors and peacemakers, where present materials are susceptible to radiation damage. ${ }^{9}$ Despite this great potential, no success has been achieved in fabricating $\mathrm{B}_{12} \mathrm{As}_{2}$ based devices up to date, presumably due to the difficulty in growing high crystalline quality $\mathrm{B}_{12} \mathrm{As}_{2}$. In this paper, we report the fabrication of $\mathrm{B}_{12} \mathrm{As}_{2} / \mathrm{SiC} p n$ diodes, and present a detailed analysis of their electrical properties.

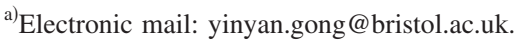

Vertical heterojunction diodes were fabricated by epitaxially depositing $\mathrm{B}_{12} \mathrm{As}_{2}$ on $300 \mu \mathrm{m}$ thick silicon-face (0001) $n$-type $4 \mathrm{H}-\mathrm{SiC}\left(n \approx 10^{18} \mathrm{~cm}^{-3}\right)$ using chemical vapor deposition (CVD) at $1350{ }^{\circ} \mathrm{C}$ under a constant total pressure of 100 Torr using $1 \% \mathrm{~B}_{2} \mathrm{H}_{6}$ in $\mathrm{H}_{2}$ and $2 \% \mathrm{AsH}_{3}$ in $\mathrm{H}_{2}$ in hydrogen atmosphere. More details on the growth and its microstructure can be found in Refs. 5 and 7. Ohmic contacts to the $\mathrm{B}_{12} \mathrm{As}_{2}$ were formed by depositing $50 \mathrm{~nm} \mathrm{Cr}$ and 100 $\mathrm{nm}$ Pt using e-beam evaporator through a shadow mask, followed by annealing at $600{ }^{\circ} \mathrm{C}$ for $10 \mathrm{~min}$ in an $\mathrm{Ar}$ ambient. ${ }^{10}$ Ohmic contacts to the $n$-type $\mathrm{SiC}$ were achieved by sputtering $100 \mathrm{~nm} \mathrm{Ni}$ through a shadow mask, followed

(a)

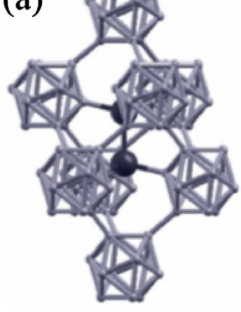

(b)
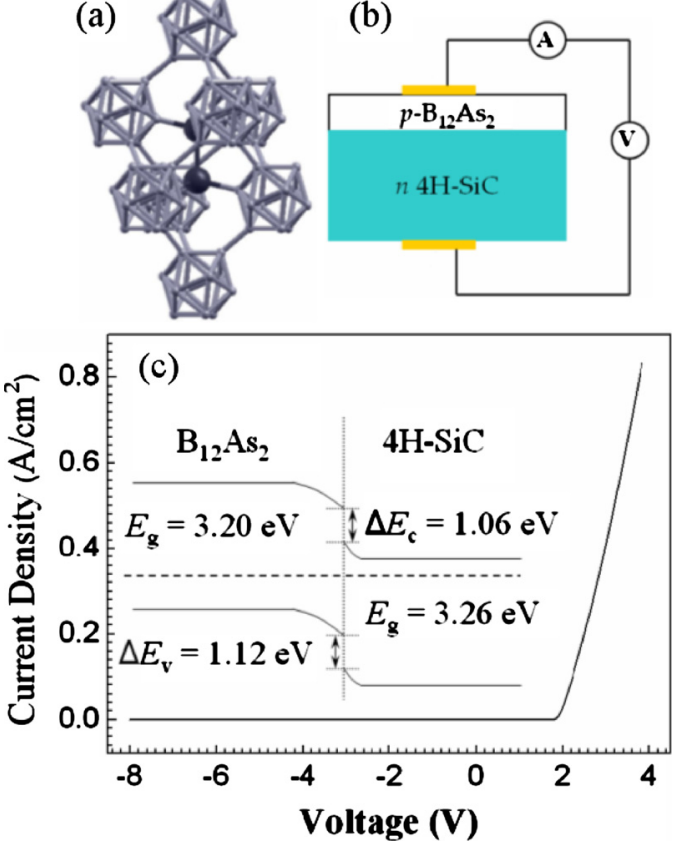

FIG. 1. (Color online) (a) Rhombohedral unit cell of $\mathrm{B}_{12} \mathrm{As}_{2}$, (b) schematic diode geometry, and (c) $I-V$ curve of a representative $\mathrm{B}_{12} \mathrm{As}_{2} / \mathrm{SiC}$ $p n$-heterojunction diode with inset showing a schematic representation of energy band diagram. 
by annealing at $950{ }^{\circ} \mathrm{C}$ for 2 min in an Ar ambient. Figure 1(b) shows a schematic of a $\mathrm{B}_{12} \mathrm{As}_{2} / \mathrm{SiC}$ heterojunction diode. The electrical properties of the diodes were characterized by current-voltage $(I-V)$ and capacitance-voltage $(C-V)$ measurements using a Keithley 4200 semiconductor characterization system. High resolution transmission electron microscopy (HRTEM) observations were carried out using a $200 \mathrm{keV}$ JEOL 2100 system at the Center for Functional Nanomaterials, Brookhaven National Laboratory.

Figure 1(c) shows the $I-V$ characteristics of a $\mathrm{B}_{12} \mathrm{As}_{2} / \mathrm{SiC}$ heterojunction with a film thickness of $4.3 \mu \mathrm{m}$, exhibiting excellent rectifying behavior with an $I_{\mathrm{F}} / I_{\mathrm{R}}$ value as high as $4.14 \times 10^{3}$ at $3 \mathrm{~V}$ indicating the formation of a $p n$ diode $\left(I_{\mathrm{F}}\right.$ and $I_{\mathrm{R}}$ stand for forward and reverse current, respectively). Hall-effect measurements on $\mathrm{B}_{12} \mathrm{As}_{2}$ films (not shown here) and previous work $^{3}$ showed that undoped $\mathrm{B}_{12} \mathrm{As}_{2}$ is usually $p$-type, and therefore when it is grown epitaxially on $n$-type $\mathrm{SiC}$, holes will diffuse from $\mathrm{B}_{12} \mathrm{As}_{2}$ into $4 \mathrm{H}-\mathrm{SiC}$ while electrons will diffuse from $4 \mathrm{H}-\mathrm{SiC}$ to $\mathrm{B}_{12} \mathrm{As}_{2}$, resulting in the formation of a depletion region and a total electrostatic potential across the junction as in a standard $p n$ junction [inset of Fig. 1(c)]. Details on the determination of the band offsets will be discussed in the following section. We note that $n$-doping of $\mathrm{B}_{12} \mathrm{As}_{2}$ has not been demonstrated to date, i.e., therefore, the approach of a heterojunction is taken here.

An ideality factor, $n$, of $\sim 1.8$ was extracted from the $I-V$ curve under forward-biased conditions of the studied $\mathrm{B}_{12} \mathrm{As}_{2} / \mathrm{SiC} p n$ diode, implying that in part recombination current may contribute to the electrical characteristics of the diode. The leakage current is $\sim 9.4 \times 10^{-6} \mathrm{~A} / \mathrm{cm}^{2}$ under a reverse bias of $0.4 \mathrm{~V}$, which however, is three orders of magnitude higher than for typical single-crystalline $4 \mathrm{H}-\mathrm{SiC} p n$ junction diodes. ${ }^{11}$ This higher leakage current can be attributed, at least partially, to structural defects due to the heteroepitaxial growth of $\mathrm{B}_{12} \mathrm{As}_{2}$ on $4 \mathrm{H}-\mathrm{SiC} . \mathrm{B}_{12} \mathrm{As}_{2}$ on $4 \mathrm{H}-$ $\mathrm{SiC}$ exhibits twin boundaries [Fig. 2(a)] perpendicular to the interface of the heterojunction. While each grain is highly crystalline [Fig. 2(b)], they are present in two distinct orientations and the boundaries between them can serve as leakage pathways in the $p n$ junction. The higher density of twin boundaries is consistent with the leakage current magnitude observed. Details on the atomic structure of twin boundaries in $\mathrm{B}_{12} \mathrm{As}_{2}$ can be found in Refs. 5 and 7. We further note the presence of a thin, relatively disordered transition layer located between the film and the substrate [Fig. 2(a)]. Trap states associated to these and other structural defects will contribute to recombination currents in the $p n$-junction. Despite the presence of these structural imperfections, good device rectifying behavior is achieved. Only a reduction in their density by recent growth improvements ${ }^{7}$ has made this possible. It is expected that the diode performance can be further improved by reducing structural defects even further. For example depositing $\mathrm{B}_{12} \mathrm{As}_{2}$ onto $m$-plane $15 \mathrm{R}-\mathrm{SiC}$ substrates can eliminate twin boundaries, ${ }^{4}$ although $n$-type $15 \mathrm{R}-$ $\mathrm{SiC}$ is presently not available commercially.

The $C-V$ measurements were performed on the $\mathrm{B}_{12} \mathrm{As}_{2} / \mathrm{SiC}$ diode from 5 to $500 \mathrm{kHz}$. The measured capacitance decreases with increasing frequency, implying that both series resistance and leakage current needed to be considered in the analysis. ${ }^{12-14} \mathrm{~A}$ three-element circuit model representing the diode is shown in the inset of Fig. 3, with $C$

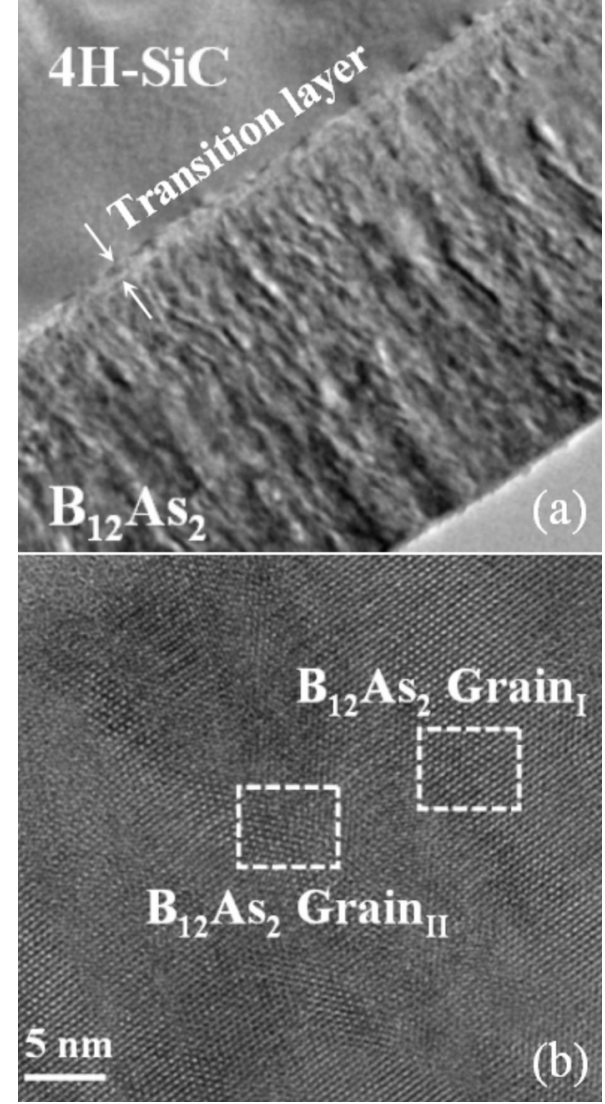

FIG. 2. (a) Cross-sectional TEM micrograph of $\mathrm{B}_{12} \mathrm{As}_{2} / 4 \mathrm{H}-\mathrm{SiC}$ heterojunction, revealing twin boundaries perpendicular to the interface. Also apparent is a transition layer between the $\mathrm{B}_{12} \mathrm{As}_{2}$ and the $\mathrm{SiC}$ substrate. (b) HRTEM micrograph of $\mathrm{B}_{12} \mathrm{As}_{2}$ grains in different orientations, labeled by the subscript I and II, respectively.

is the actual frequency-independent diode capacitance, $R_{\mathrm{S}}$ is the series resistance, and $R_{\mathrm{p}}$ is the effective diode resistance due to leakage current. From a single measurement of impedance, only two of these three parameters may be determined. To consider both the series resistance and the leakage current, a two-frequency $C-V$ technique by Yang and $\mathrm{Hu}^{14}$ was used to extract $C$ using the following expression:

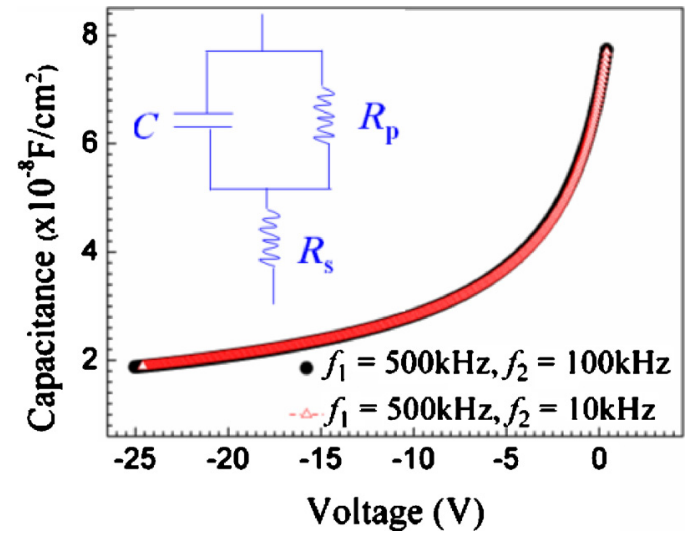

FIG. 3. (Color online) $C-V$ data analyzed using the two-frequency technique, considering the simultaneous presence of both series resistance and leakage current, with inset showing the equivalent circuit model for the $p n$ diode. 


$$
C=\frac{f_{1}^{2} C_{1}\left(1+D_{1}^{2}\right)-f_{2}^{2} C_{2}\left(1+D_{2}^{2}\right)}{f_{1}^{2}-f_{2}^{2}},
$$

where $C_{1}$ and $C_{2}$ are the capacitance measured at the frequency $f_{1}$ and $f_{2}$, respectively, $D_{1}\left(=G_{1} / 2 \pi f_{1} C_{1}\right)$ and $D_{2}$ $\left(=G_{2} / 2 \pi C_{2}\right)$ are the dissipation at the frequency $f_{1}$ and $f_{2}$, respectively, $G_{1}$ and $G_{2}$ are the diode conductance at the frequency $f_{1}$ and $f_{2}$, respectively. Figure 3 shows the determined diode capacitance with $f_{1}=500 \mathrm{kHz}$ and $f_{2}$ $=100 \mathrm{kHz}$, and $f_{1}=500 \mathrm{kHz}$ and $f_{2}=10 \mathrm{kHz}$, with both data sets in good agreement, illustrating that the technique is applicable to the $C-V$ measurement on $\mathrm{B}_{12} \mathrm{As}_{2} / \mathrm{SiC} p n$ diode.

Under the assumption of abrupt junction, the hole concentration in $\mathrm{B}_{12} \mathrm{As}_{2}$ film is given by

$$
N_{A}(W)=2\left[q \varepsilon_{s} A^{2} \frac{d\left(1 / C^{2}\right)}{d V}\right]^{-1},
$$

where $q$ is the electron charge, $\varepsilon_{s}[\approx 7.15$ (Ref. 1) $]$ is the permittivity of $\mathrm{B}_{12} \mathrm{As}_{2}, A$ is the junction area, and $W$ $\left(=\varepsilon_{s} A / C\right)$ is depletion layer width. ${ }^{13}$ With the free hole concentration in $\mathrm{B}_{12} \mathrm{As}_{2}$ typically much lower than the free electron concentration in $n$-type $4 \mathrm{H}-\mathrm{SiC}$ substrate, for simplicity, we neglect the spreading of space-charge region into the substrate. The determined free hole concentration in the $\mathrm{B}_{12} \mathrm{As}_{2}$ film is in the range of $\sim 1.8-2.0 \times 10^{17} \mathrm{~cm}^{-3}$, with a slightly higher density near the interface, which might be due to the existence of the interfacial layer between $\mathrm{B}_{12} \mathrm{As}_{2}$ and the $4 \mathrm{H}-\mathrm{SiC}$.

The built-in potential of the diodes, extracted by extrapolating $1 / C^{2}$ versus $V$ as $1 / C^{2}$ to zero, is $\sim 1.89 \mathrm{~V}$. According to Anderson's energy band model, ${ }^{15}$ the band offsets of a heterojunction can be estimated using the following expression: $\Delta E_{c}=q V_{\mathrm{bi}}-E_{g 1}+\left(\delta_{v 1}+\delta_{c 2}\right)$, where $\delta_{v}\left(\delta_{c}\right)$ is the separation between Fermi level and valence band (conduction band), and subscript 1 and 2 referred to $\mathrm{B}_{12} \mathrm{As}_{2}$ and $\mathrm{SiC}$, respectively. Given the energy band gap of $4 \mathrm{H}-\mathrm{SiC}$ $(\sim 3.26 \mathrm{eV}),{ }^{16}$ the estimated band offsets are $\sim 1.06 \mathrm{eV}$ and $1.12 \mathrm{eV}$ for conduction band and valance band, respectively [inset of Fig. 1(c)]. Although this can only serve as rough estimation, the knowledge of band alignment is important for the future work on $\mathrm{B}_{12} \mathrm{As}_{2}$ device applications.

In conclusion, we have successfully demonstrated $\mathrm{B}_{12} \mathrm{As}_{2} / 4 \mathrm{H}-\mathrm{SiC} p n$ heterojunction diodes by depositing
$\mathrm{B}_{12} \mathrm{As}_{2}$ on $n$-type $4 \mathrm{H}-\mathrm{SiC}$ by CVD. Electrical properties of the diodes were characterized by $I-V$ and $C-V$ measurements. A good rectifying behavior was observed which confirms the formation of $p n$ heterojunction diode. A two-frequency technique was employed to analyze $C-V$ data, and the obtained free hole concentration in the $\mathrm{B}_{12} \mathrm{As}_{2}$ film is $\sim 1.8-2.0$ $\times 10^{17} \mathrm{~cm}^{-3}$, and the band offsets are $\sim 1.06 \mathrm{eV}$ and 1.12 $\mathrm{eV}$ for conduction band and valance band, respectively.

The authors gratefully acknowledge the support by the Engineering and Physical Science Research Council (EPSRC) under Grant No. EP/D075033/1, by the National Science Foundation Materials World Network Program under Grant No. 0602875 under the NSF-EPSRC Joint Materials Program, and by the U.S. Department of Energy under Contract No. DE-AC02-98CH10886.

${ }^{1}$ S. Bakalova, Y. Gong, C. Cobet, N. Esser, Y. Zhang, J. H. Edgar, Y. Zhang, M. Duddley, and M. Kuball, Phys. Rev. B 81, 075114 (2010).

${ }^{2}$ D. Emin, Phys. Today 40(1), 55 (1987).

${ }^{3}$ D. Emin, J. Solid State Chem. 177, 1619 (2004).

${ }^{4}$ H. Chen, G. Wang, M. Dudley, Z. Xu, J. H. Edgar, T. Batten, M. Kuball, L. Zhang, and Y. Zhu, Appl. Phys. Lett. 92, 231917 (2008).

${ }^{5}$ H. Chen, G. Wang, M. Dudley, L. Zhang, L. Wu, Y. Zhu, Z. Xu, J. H. Edgar, and M. Kuball, J. Appl. Phys. 103, 123508 (2008).

${ }^{6}$ D. Emin, J. Solid State Chem. 179, 2791 (2006); G. A. Slack, T. M. McNelly, and E. A. Taft, J. Phys. Chem. Solids 44, 1009 (1983).

${ }^{7}$ R. Nagarajan, Z. Xu, J. H. Edgar, F. Baig, J. Chaudhuri, Z. Rek, E. A. Payzant, H. M. Meyer, J. Pomeroy, and M. Kuball, J. Cryst. Growth 273, 431 (2005).

${ }^{8}$ V. F. Sears, Neutron News 3, 26 (1992).

${ }^{9}$ B. Danilchenko, A. Kudnyk, L. Shpinar, D. Poplavskyy, S. E. Zelensky, K. W. J. Barnham, and N. J. Ekins-Daukes, Sol. Energy Mater. Sol. Cells 92, 1336 (2008); P. Rappaport, Phys. Rev. 93, 246 (1954); R. L. Statler, Radiat. Eff. Defects Solids 4, 305 (1970).

${ }^{10}$ S. H. Wang, E. M. Lysczek, B. Liu, S. E. Mohney, Z. Xu, R. Nagarajan, and J. H. Edgar, Appl. Phys. Lett. 87, 042103 (2005).

${ }^{11}$ F. Moscatelli, A. Scorzoni, A. Poggi, M. Bruzzi, S. Sciortino, S. Lagomarsino, G. Wagner, I. Mandic, and R. Nipoti, IEEE Trans. Nucl. Sci. 53, 1557 (2006).

${ }^{12}$ G. I. Roberts and C. R. Crowell, J. Appl. Phys. 41, 1767 (1970); Y. Wang, K. P. Cheung, R. Choi, and B. H. Lee, IEEE Trans. Electron Devices 55, 2429 (2008).

${ }^{13}$ D. K. Schroder, Semiconductor Material and Device Characterization, 3rd ed. (Wiley, New York, 2006).

${ }^{14}$ K. J. Yang and C. Hu, IEEE Trans. Electron Devices 46, 1500 (1999).

${ }^{15}$ R. L. Anderson, Solid-State Electron. 5, 341 (1962); J. P. Donnelly and A. G. Milines, IEEE Trans. Electron Devices 14, 63 (1967).

${ }^{16}$ C. Persson and U. Lindefelt, Phys. Rev. B 54, 10257 (1996). 